\title{
Optical properties of dye DN-F01 as sensitizer
}

\author{
Febrina Ramadhani $^{1}$, Agus Supriyanto ${ }^{2}$, Mohd Khairul Bin Ahmad ${ }^{3}$, Nadiyah El- \\ Haq Diyanahesa ${ }^{1}$, Diani Galih Saputri ${ }^{1}$ \\ ${ }^{1}$ Postgraduate Student of Physics, Sebelas Maret University, Jl. Ir. Sutami no \\ 36 Kentingan Surakarta, Indonesia \\ ${ }^{2}$ Department of Physics, Sebelas Maret University, Jl. Ir. Sutami no 36 Kentingan Surakarta \\ ${ }^{3}$ Department of Electronics Engineering, Universiti Tun Hussein Onn Malaysia, 86400 Parit \\ Raja, Johor, Malaysia \\ Email: ${ }^{1}$ ramadhanifebii@gmail.com
}

Received 7 February 2019, Revised 10 March 2019, Published 29 March 2019

\begin{abstract}
Dye-Sensitized Solar Cell (DSSC) is a solar cell made from organic material that works with an electrochemical photo system to convert solar energy into electrical energy. The components of DSSC consist of transparent conductive substrates, dyes, semiconductors, electrolytes and counter electrodes. Dye as a sensitizer is has an important role in DSSC performance improvement. This study aims to obtain optical characterization such as absorbance spectrum and transmittance from DSSC using dye DNF01 with concentration $2 \times 10^{-3} \mathrm{M}$. Optical characterization has been tested using a UV-VIS Spectrophotometer Shimadzu UV-1800. The test results show that the absorbance spectrum of the dye is at a wavelength of 400-500 $\mathrm{nm}$. Band gap energy of DN-F01 has obtained from its absorbance and transmittance value is about $2,46 \mathrm{eV}$.
\end{abstract}

Keywords: DSSC, DN-F01, absorbance, transmittance, band gap energy.

\section{Introduction}

Nowadays energy has become one of the basic needs that sustain human life. All activities carried out do not escape from the use of energy. The use of energy is currently still dominated by non-renewable energy whose supplies are running low. To reduce dependence on the use of non-renewable energy sources, alternative energy from renewable energy is needed. One of the potential energy to be used as alternatives is solar energy.

Solar cells convert solar energy into electrical energy. Solar cells have advantages such as abundant solar energy sources, the principle of operation is not dangerous, does not cause environmental pollution and installation systems that are easily applied anywhere (Sashank et al., 2017). The solar cell device which is currently being developed and researched by experts is Dye-Sensitized Solar Cell (DSSC). The ideal DSSC contains a combination of transparent conductive substrates that are sensitive to dyes, semiconductor films, dyes, electrolytes and electrodes (Husain et al., 2018) such as the DSSC scheme sketch shown in Figure 1. 


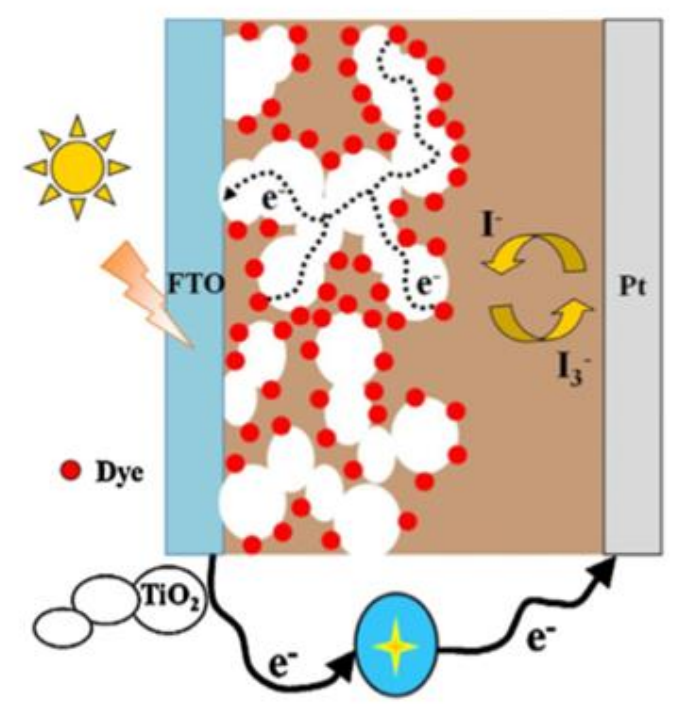

Figure 1. DSSC Scheme (Lee et al., 2017)

In DSSC, dye as a sensitizer plays a key role in absorbing sunlight and converting solar energy into electrical energy (Oviri \& Ekpunobi, 2013). Dye has several conditions to be apply to the DSSC, such as the absorption spectrum must cover the entire visible region including the near-infrared region (NIR), the dye must have a holding group to bind it to the semiconductor surface, an oxidation state that is more positive than the redox potential of the electrolyte, the potential of the Highest Occupied Molecular Orbital (HOMO) dye must be positive enough compared to the potential redox electrolyte for efficient dye regeneration, the potential of the lowest Unoccupied Molecular Orbital (LUMO) dye must be negative enough to match the potential edge of the semiconductor conduction band and its orbitals must be placed in the acceptor's lowest dyes to provide efficient electron injection (Hagberg et al., 2017; Husain et al., 2018; Latini, 2018).

To improve the performance of DSSC solar cells, the selection of the right dye as a light absorber is needed. Synthetic organic dye is a type of dye that has been studied quite a lot to be applied to DSSC solar cell devices. Synthetic organic dye is made from synthetic resources such as chemicals, petroleum byproducts, and minerals. Synthetic organic dye produces a dye that is consistent compared to natural dye extraction of plants whose colors tend not to be exactly the same in hue and intensity (Ziarani et al., 2018). In addition, synthetic organic dye has a higher electron movement and is not easily degraded (Li et al., 2013).

In this research, a synthetic organic dye DN-F01 (yellow dye) which has a molecular structure as shown in Figure 2. Dye solution was characterized using UV-Vis spectrophotometer to determine the optical properties of DN-F01. 


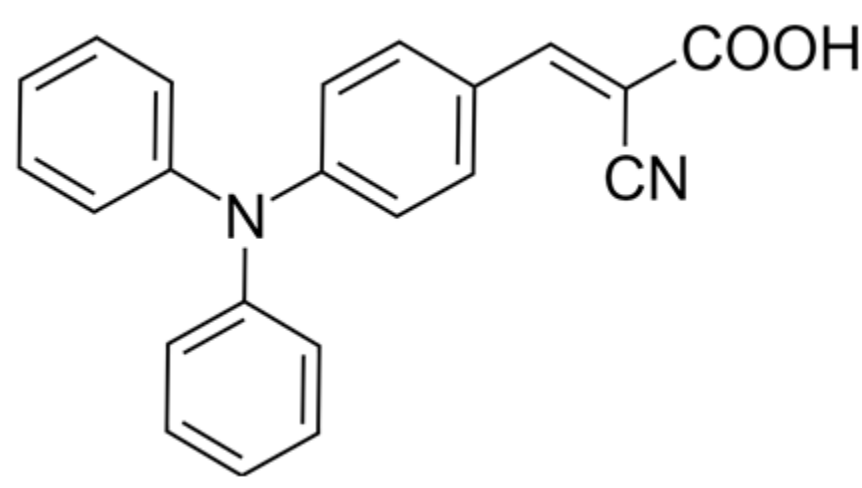

Figure 2. DN-F01 Molecular Structure

\section{Research Methods}

\subsection{Preparation of the DN-F01 Solution}

DN-F01 of 0.001 gram was put into the reagent bottle and then dissolved with $5 \mathrm{ml}$ of ethanol. The dye is then stirred at $350 \mathrm{rpm}$ at $40^{\circ} \mathrm{C}$ for 1 hour until it is homogeneous.

\subsection{Optical Characterization DN-F01}

The DN-F01 solution was characterized using the UV-VIS Spectrophotometer Shimadzu UV-1800. UV-VIS spectroscopy is a measurement technique in which the recording of absorption spectra from different samples using ultraviolet (UV) and visible (VIS) light is achieved with a spectrophotometer. UV-VIS spectroscopy is usually applied to organic molecules, inorganic or complex ions in solution, as well as solid materials such as film or glass.

This optical characterization was carried out to obtain the absorbance and transmittance values of DN-F01. The results obtained are in the form of absorption spectra with absorbance values at each wavelength. The absorbance and transmittance values obtained will be used to determine the energy gap of DN-F01.

\section{Results and Discussion}

DN-F01 solution was tested using a UV-Vis spectrophotometer with absorbance spectrum measured in the wavelength range of 300-800 nm. In general, photosensitizer or dye has fundamental characteristics of the absorption spectrum must cover the entire visible light region and even near infrared light (Mohsen et al., 2017). Caro (2015) mentions that the spectrum of visible light ranges from wavelengths of 390-780 $\mathrm{nm}$. The absorbance value of DN-F01 that has been characterized can be seen in the graph shown in Figure 3. From the graph it can be seen that DN-F01 can absorb visible light in the wavelength range of 400-500 $\mathrm{nm}$. There are several absorbance peaks with the highest peak at a wavelength of $415.05 \mathrm{~nm}$ with an absorbance of 3.94. The second peak at wavelength is $430.91 \mathrm{~nm}$ with absorbance of 3.48. The third peak with a wavelength of 
$439.14 \mathrm{~nm}$ with an absorbance of 3.46. The fourth peak with a wavelength of $468.97 \mathrm{~nm}$ with an absorbance of 3.43 .

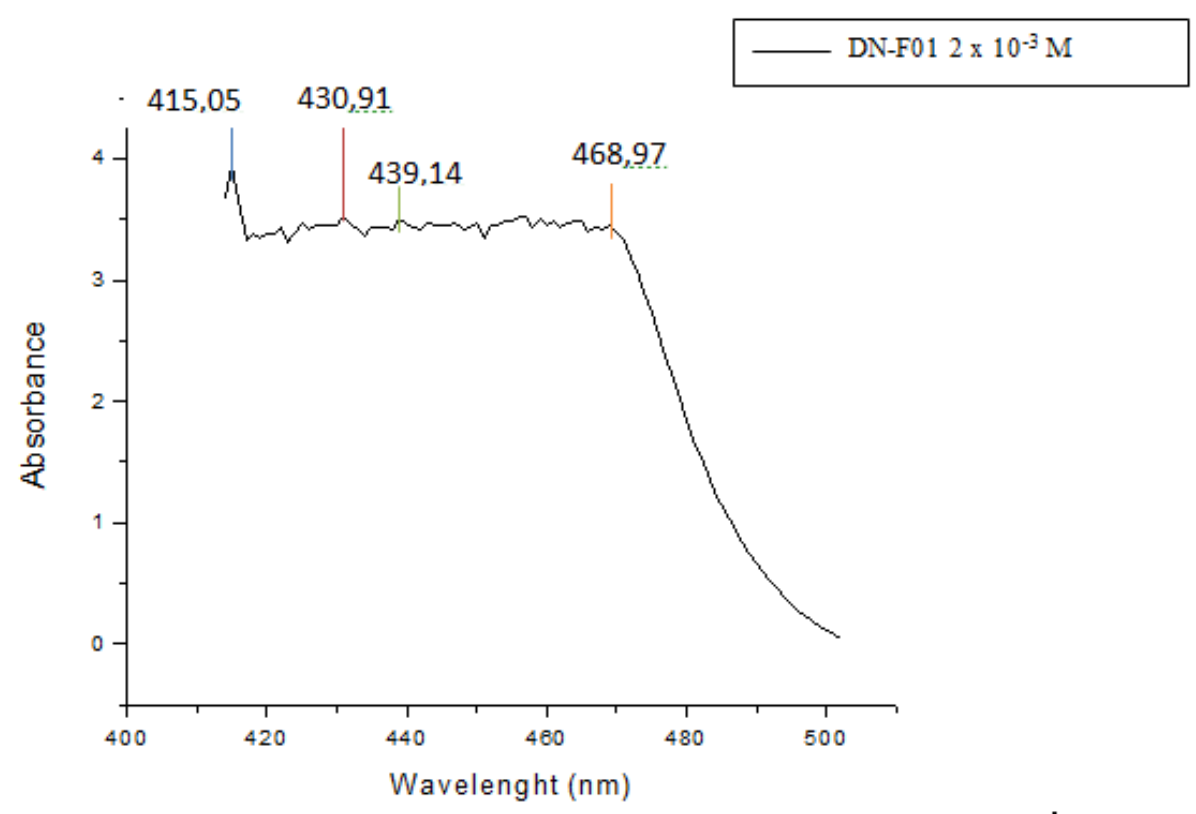

Figure 3. DN-F01 Absorbance Spectrum

In addition to the absorbance value, UV-Vis characterization spectrophotometer also provides transmittance values. Transmittance is a fraction of the incident light or other electromagnetic radiation at certain wavelengths that pass through a sample (Oviri \& Ekpunobi, 2013). The transmittance equation can be written as follows:

$$
T=\frac{I}{I_{O}}
$$

Absorbance (A) and transmittance (T) are related to one another. The relationship between absorbance and transmittance is illustrated in Figure 4.

$\%$ Transmittance

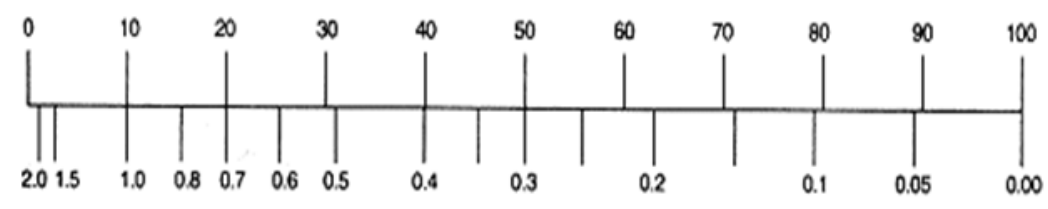

Absorbance

Figure 4. Relationship of Absorbance and Transmittance

So, if all the light passes through the solution without absorption, the absorbance is zero, and the percent transmittance is $100 \%$. If all the light is absorbed, the percent transmission is zero, and the absorption is unlimited. This shows that the absorbance value $(A)$ is inversely proportional to the transmittance value $(T)$ which can be written in the form of the following equation: 


$$
A=\log \frac{1}{T}
$$

The transmittance value of DN-F01 is shown in Figure 5. From Figure 5. it can be seen that the transmittance value has increased in the wavelength range of 480-500 nm with the highest transmittance of about 94\%. The transmittance graph is inversely proportional to the absorbance graph. On the transmittance graph the value of the largest transmittance wavelenght increases, while on the absorbance graph the wavelength of the absorbance value decreases.

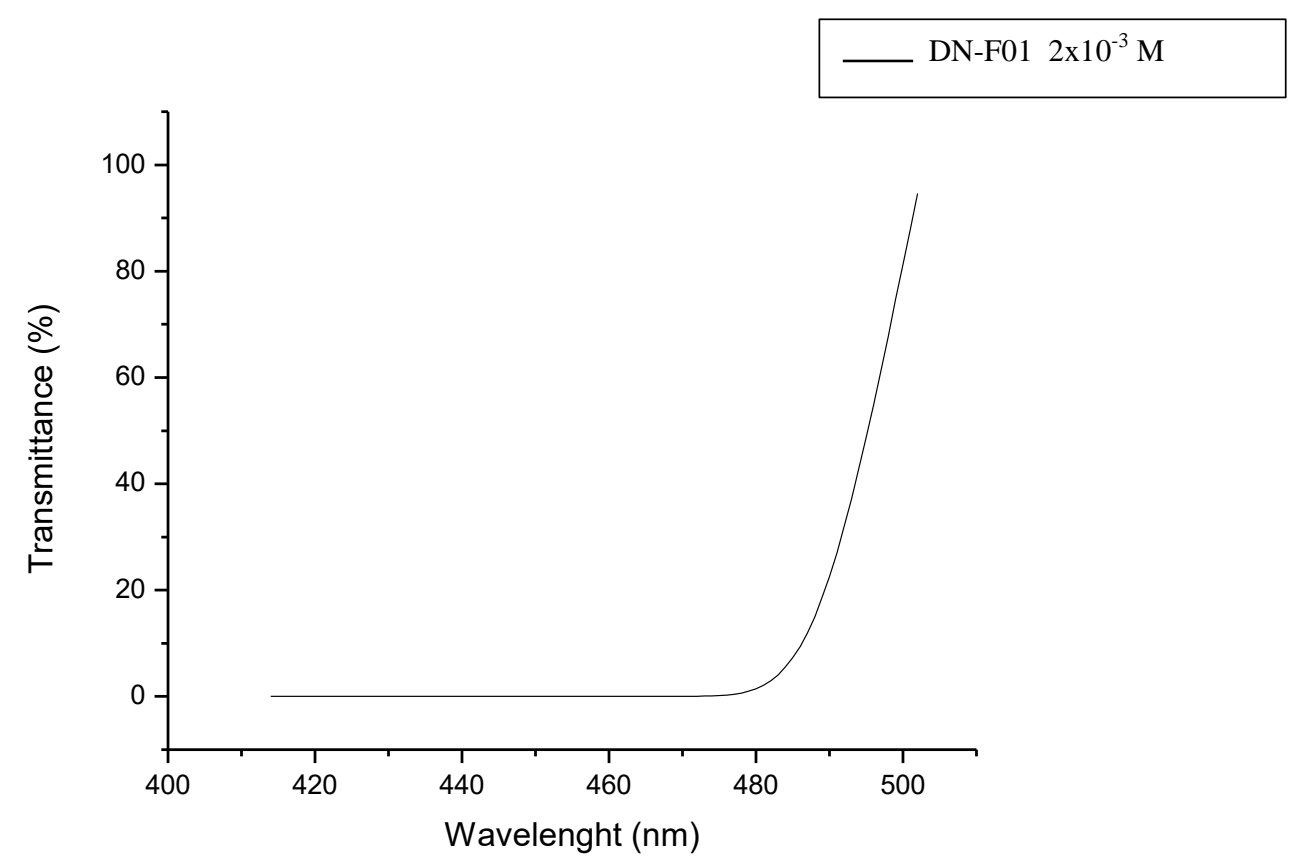

Figure 5. DN-F01 transmittance

From the transmittance data obtained from the UV-Vis spectrophotometer characterization, the magnitude of the optical absorbance coefficient $(\alpha)$ can be calculated which can then be used to graph the relationship between the photon energy of the hv and $(\alpha h v)^{1 / 2}$ to obtain the energy value of the gap band DN-F01. Band gap energy is the minimum energy needed to transition electrons from the valence band to the known conduction band (Myat \& Khine, 2018).

From Figure 6. it can be seen that the energy gap DN-F01 is $2.46 \mathrm{eV}$. The gap energy value obtained is smaller than the anatase phase semiconductor gap anatase phase which is worth $3.2 \mathrm{eV}$. This is due to the charge separation occurs in DSSC solar cells where when absorbing photon energy from visible light, the electrons in the dye will be excited from the HOMO state to the LUMO region which will then be transferred to the $\mathrm{TiO} 2$ semiconductor conduction band. 


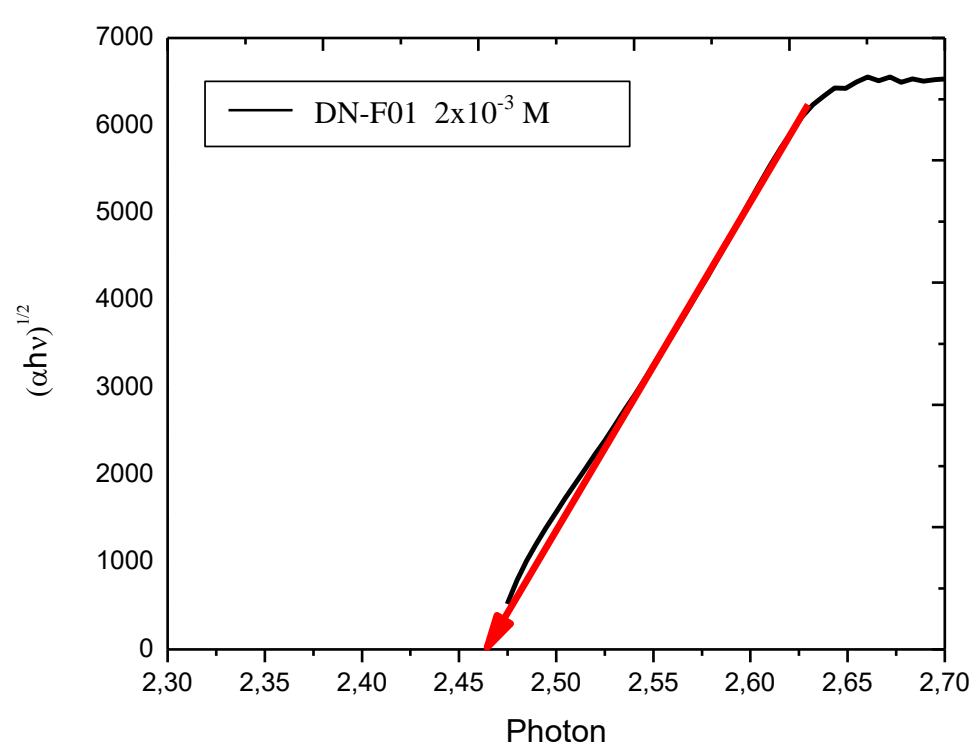

Figure 6. Graph of photon - ( $\alpha$ hv) $1 / 2$ as a function of the energy gap DN-F01

\section{Conclusions}

From the data and discussion above it can be concluded that the DN-F01 dye can be used as a sensitizer in DSSC solar cells because it has absorption at visible wavelengths, namely in the wavelength range of 400-500 $\mathrm{nm}$ and an energy gap of about $2.46 \mathrm{eV}$.

\section{Acknowledgements}

Higher Education Basic Research Contract with 2019 Budget Year Research Contract No: 092 / SP2H / LT / DRPM / 2019

\section{Reference}

Caro, Coslimo. 2015. UV/VIS Spectrophotometry - Fundamentals and Application. Mettler-Toledo Publication. https://www.researchgate.net/publication/321017142

Hagberg, D., Marinado, T., Karlsson, K., Nonomura, P., Boschloo, G., Brinck, T., Hagfeldt, A., Sun, L. 2007. Tuning the HOMO and LUMO Energy Levels of Organic Chromophores for Dye Sensitized Solar Cells. Journal Organic Chemistry, vol. 72, pp. 9950-9956. https://doi.org/10.1021/jo701592x

Husain, AAF., Hasan, WZ., Shafie, S., Hamidon, M., Pandey, SS. 2018. A Review of Transparent Solar Photovoltaic Technologies. Renewable and sustainable energy reviews, vol. 94, hlm. 779-791. https://doi.org/10.1016/j.rser.2018.06.031

Latini, A., Panetta, R. 2018. Test of Different Sensitizing Dyes in Dye-Sensitized Solar Cells Based on $\mathrm{Nb}_{2} \mathrm{O}_{5}$ Photoanodes. Energies, 11, 975. https://doi.org/10.3390/en11040975

Lee, CP., Li, CT., Ho, KC. 2017. Use of Organic Materials in Dye-sensitized Solar 
Cells. Materials Today, vol. 20, pp 267-283. https://doi.org/10.1016/j.mattod.2017.01.012

Li, W., Liu, B., Wu, Y., Zhu, S., Zhang, Q., Zhu, W. 2013. Organic Sensitizer Incorporating 3,4-Ethylenedioxythiophene as The Conjugated Bridge: Joint Photophysical and Electrochemical Analysis of Photovoltaic Performance. Dye and Pigment, vol. 99, hlm. 176-184. https://doi.org/10.1016/j.dyepig.2013.04.031

Mohsen, M K., Fraih, M R., J H, Nahida., Lateef, K H. 2017. Spectrophotometric Study of Dyes for Dye Sensitized Solar Cell (DSSC). Journal of Global Pharmacy Technology, vol. 12(9), pp. 206-212. https://www.researchgate.net/publication/328827833

Myat, S., Khine, S N. 2018. Optical Properties of Dye Solutions for Dye-Sensitized Solar Cell. International Journal of Scientific and Research Publications, Vol. 8, Issue. 12, pp. 32-36. http://dx.doi.org/10.29322/IJSRP.8.12.2018.p8407

Oviri. K., Ekpunobi, J. 2013. Transmittance and Band Gap Analysis of Dye Sensitized Solar Cell. Research Journal of Recent Sciences, vol. 2(1). pp. 25-31. https://pdfs.semanticscholar.org

Sashank, T., Manikanta, B., Pasula, Aparna. 2017. Fabrication and Experimental Investigation on Dye Sensitized Solar Cells Using Titanium Dioxide Nano Particles. Material Today: Proceedings, pp. 3918-3925. https://doi.org/10.1016/j.matpr.2017.02.291

Ziarani, GM., Moradi, R., Lashgari, N., Kruger, HG. 2018. Metal- Free Synthetic Organic Dyes. Elsevier. https://doi.org/10.1016/C2017-0-03672-8 